\title{
Erratum to: Biological consequences of zinc deficiency in the pathomechanisms of selected diseases
}

\author{
Kamil Jurowski $^{1,2}$ • Bernadeta Szewczyk ${ }^{3}$ - Gabriel Nowak ${ }^{3,4}$. \\ Wojciech Piekoszewski ${ }^{1,5}$
}

Published online: 1 September 2015

(C) SBIC 2015

\section{Erratum to: J Biol Inorg Chem (2014)}

19:1069-1079

DOI: 10.1007/s00775-014-1139-0

Unfortunately, in the original publication, the value of total zinc content of plasma statement was incorrectly published under the heading 'The physiological function of zinc'.

The correct statement should read as:

The total zinc content of plasma is usually approximately $100 \mu \mathrm{g}$ zinc/100 $\mathrm{mL}$ of plasma depending on (1) age, (2) pregnancy, (3) sex, and (4) time of day as the plasma zinc content is higher in the morning than in the afternoon [10].

The online version of the original article can be found under doi:10.1007/s00775-014-1139-0.

Wojciech Piekoszewski

wojciech.piekoszewski@uj.edu.pl

1 Department of Analytical Chemistry, Faculty of Chemistry, Jagiellonian University, R. Ingardena 3, 30-060 Kraków, Poland

2 Malopolska Centre for Translational Medicine, Faculty of Medicine, Jagiellonian University Collegium Medicum, Kraków, Poland

3 Institute of Pharmacology, Polish Academy of Sciences, Kraków, Poland

4 Faculty of Pharmacy, Jagiellonian University Collegium Medicum, Kraków, Poland

5 Laboratory of High Resolution Mass Spectrometry, Regional Laboratory of Physicochemical Analysis and Structural Research, Faculty of Chemistry, Jagiellonian University, Kraków, Poland 